\title{
Parking as a loss leader at shopping malls
}

\author{
Fulya Yuksel Ersoy ${ }^{\mathrm{a}, 1}$, Kevin Hasker ${ }^{\mathrm{b}, 2}$, Eren Inci ${ }^{\mathrm{c}, *}$ \\ a Department of Economics, Stanford University, 579 Serra Mall, Stanford, CA 94305, USA \\ ${ }^{\mathrm{b}}$ Department of Economics, Bilkent University, Bilkent, 06800 Ankara, Turkey

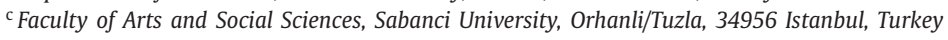

\section{A R T I C L E I N F O}

\section{Article history:}

Received 14 August 2015

Revised 21 April 2016

Accepted 22 April 2016

Available online 17 May 2016

\section{Keywords:}

Bundling

Loss-leader pricing

Mode choice

Public transportation

Shopping mall parking

\begin{abstract}
A B S T R A C T
This paper investigates the pricing of malls in an environment where shoppers choose between a car and public transportation in getting to a suburban mall. The mall implicitly engages in mixed bundling; it sells goods bundled with parking to shoppers who come by car, and only goods to shoppers who come by public transportation. There are external costs of discomfort in public transportation due to crowdedness. Thus, shoppers using public transportation deter each other. The mall internalizes these external costs, much like a policy maker. To do so, it raises the sales price of the good and sets a parking fee less than parking's marginal cost. Hence, parking is always a loss leader. Surprisingly, this pricing scheme is not necessarily distortionary.
\end{abstract}

(C) 2016 Elsevier Ltd. All rights reserved.

\section{Introduction}

Parking is costly to provide, ${ }^{3}$ yet most shopping malls provide plentiful parking for free or with only nominal fees. ${ }^{4}$ In a model of a suburban shopping mall, where shoppers can choose between a car and public transportation, we show that the equilibrium parking fee the mall chooses can be positive or zero, but it is always less than the marginal cost of providing a parking space. It is well known that retailers commonly price key goods for a holiday or specific season very low-possibly below costs-in order to attract customers. An established literature shows why such "loss-leader" practices can be profitable (see, e.g., Chen and Rey, 2012; DeGraba, 2006; Ellison, 2005; Hess and Gerstner, 1987; In and Wright, 2014; Lal and Matutes, 1994). We show that the mall always prices parking below its cost.

In our simple model, a monopolist shopping mall chooses the sales price for a good and the fee for the parking spaces it provides. Customers choose whether to visit the mall for shopping and then whether to use a car or public transportation. One of the defining properties of public transportation is discomfort costs associated with crowdedness, ${ }^{5}$ which we incorporate into our model in a fashion similar to Kraus (1991) and de Palma et al. (2015). These costs are external in the sense

\footnotetext{
* Corresponding author. Tel.: +90 216483 9340; fax: +90 2164839250.

E-mail addresses: fulya@stanford.edu (F.Y. Ersoy), hasker@bilkent.edu.tr (K. Hasker), ereninci@sabanciuniv.edu (E. Inci).

1 Tel.: +1 6506468934 .

2 Tel.: +90 312290 1875; fax: +903122665140.

3 A typical mall allocates 4-6 parking spaces per 1000 square feet of gross leasable area, which translates into an area larger than the area it allocates for stores.

${ }^{4}$ In a survey of US malls by the International Council of Shopping Centers and Urban Land Institute (2003), 94\% of the malls stated that they charge no fee for parking, and only $2 \%$ stated that they charge a fee for parking. The remaining $4 \%$ did not respond.

5 As shown in Parry and Small (2009), comfort is one of the main factors affecting commuting preferences. Li and Hensher (2011), Haywood and Koning (2013), and Kroes et al. (2013) quantify such crowding costs in public transportation for various cities.
} 
that any additional passenger contributes to the discomfort of all others, and he does not care about others' discomfort; no one else will either. Then, each shopper using public transportation will deter each other and the mall suffers. What can the mall do to deal with this crowding-out effect? The best it can do is to have public transportation users internalize the discomfort externalities that they impose on each other. Otherwise, the mall would be shooting itself in the foot. By doing so, it converts external costs into a higher willingness to pay. Thus, it has incentives to internalize such congestion effects, much like a policy maker, even though it is a profit maximizer. The mall's motivation is the same as a private road operator in setting road tolls (see, e.g., de Palma and Lindsey, 2000; Verhoef et al., 1996), or a monopolist airline carrier in scheduling its flights (see, e.g., Brueckner, 2002).

How exactly can the mall cause shoppers to internalize discomfort costs? The only way is to raise the sales price of the good by the amount of external cost that each public transportation user generates, which will then induce the "right" number of public transportation riders to visit the mall. However, a shopper who travels to the mall by car is now penalized, even though he does not impose any externality on others (of course, cars create external costs of traffic congestion, but these costs are negligible for suburban malls). Then the mall should decrease the parking fee by the same amount. This means that the parking fee will be less than the marginal cost of providing a parking space. Thus, the mall's internalization of crowding externalities effectively encourages car usage. Consequently, parking is priced as a loss leader, thus at least some of the costs of parking are embedded in the sales price of the good offered at the mall. If the marginal cost of parking is sufficiently low, which is usually the case for suburban areas where land is cheap, then parking can even be free. Surprisingly, this pricing scheme is not necessarily distortionary; having parking as a loss leader can be welfare maximizing. Even more surprisingly, loss-leader pricing occurs even when there are passengers who use public transportation for reasons other than shopping at the mall and when the mall sells multiple goods.

Our base model is a suburban mall because we assume that cars do not create any significant traffic congestion around the mall. In reality, incoming and outgoing car traffic is an external cost to everyone including the mall's customers themselves. In an extension, in addition to the external costs of discomfort in public transportation, we allow for external trafficcongestion costs that cars impose on each other, which is more of a concern for urban malls. In such an environment, there is a horse race between externalities. Parking is still a loss leader if the marginal external cost of discomfort in public transportation is higher than the marginal external cost of traffic congestion that cars create. In another extension, we show that our result is robust for the private provision of transportation service to the mall. In yet another extension, we verify that the mall still internalizes the crowding costs if it offers transportation service on its own. We also provide two reduced-form models of competition between malls.

While there is a large literature on the economics of parking in general (see Arnott et al., 2011 and Inci, 2015, for reviews), there has been little focus on the topic of shopping mall parking. Hasker and Inci (2014) provide an independent answer to why shopping mall parking is so cheap. That paper points out that, since shopping is a search activity, free parking provides a type of insurance to shoppers for the risk that they take by visiting the mall and searching for a good. Hence, the mall embeds the parking costs in the sales price rather than charging a separate fee for parking. In our setting, the mall prices parking as a loss leader and embeds at least some of its costs in the sales price of the good so that shoppers internalize the crowding effect in public transportation. If the insurance mechanism worked out in Hasker and Inci (2014) is combined with the internalizing-the-congestion-externality mechanism we provide in this paper, this would produce even further downward pressure on shopping mall parking fees.

Part of the literature has shown that parking is an important factor in where people shop. Lindsey and West (1997) find that providing parking coupons, which favor suburban customers over customers based downtown, can be collectively profitable for downtown retailers, although it is not individually rational for each store to participate in such a program. Lindsey and West (1998) make an empirical assessment of such a price-discrimination scheme in Edmonton, Canada, showing that it helped downtown retailers attract customers away from suburban shopping malls. Van Ommeren et al. (2014) concentrate on the opposite price-discrimination policy of parking permits in shopping districts, which favors residents over nonresidents, the latter of whom usually visit downtown for shopping. They estimate that parking permits result in a yearly welfare loss of about $15 \%$ of parking supply costs, most of which is due to the decrease in nonresidents' consumer surplus.

By employing a stated-preference approach, Borgers and Vosters (2011) show that parking fees are extremely important in shoppers' preferences between two shopping mall alternatives. Hensher and King (2001) obtain a similar result for parking fees at shopping districts. In fact, one of the advantages of shopping malls against downtown shopping areas is their parking supply (Reimers, 2013). De Borger and Russo (2015) show that underpriced on-street parking in downtown areas is an outcome of lobbying by downtown merchants (who want lower on-street parking fees) and suburban malls (who want higher on-street parking fees). From survey data, Hu and Saleh (2005) find that many people would visit downtown more often to shop if parking was cheaper, easier, and more abundant.

In terms of mode choice and parking fees, Gillen (1977) finds that the impact of parking costs on mode choice is greater than that of car-running costs, and that this remains true even when income effects are taken into account. Van der Waerden et al. (2009) concentrate on the short-term implications of a transition from free parking to paid parking in a regional shopping mall in the Netherlands. They find that customers change their travel modes and shopping locations and decrease their visit frequencies and durations as well as expenditures. The impact of parking fees on total car usage is indeterminate. Glazer and Niskanen (1992) point out that time-based parking fees can increase total traffic by decreasing the duration of visits. Voith (1998) discusses the interplay between parking, transportation, and land use and also finds a non-monotonic 
relationship between parking fees and car usage. In particular, depending on the parameters, parking fees may increase or decrease car usage.

When shopping mall parking is free, its costs are embedded in the costs of goods and services provided at the mall. A strand of the literature on parking focuses on a general analysis of how parking costs are embedded in the prices of other goods and services. Van Ommeren et al. (2011), Manville (2013), and Bakis et al. (2015) show that the costs of free onand off-street parking get embedded in housing prices and rents. Van Ommeren and Wentink (2012) underline that many employers prefer to provide free parking spaces to their employees rather than higher wages because parking spaces are not taxed as a benefit, unlike wages.

We get parking as a loss leader in a complete information environment. Most prior work justifies loss-leader pricing in incomplete information settings. ${ }^{6}$ For example, Hess and Gerstner (1987) assume that only the price of the loss-leader good is advertised, then the store makes its profits out of other goods. Lal and Matutes (1994) argue that this strategy economizes on advertising costs. DeGraba (2006) analyzes it as a form of second-degree price discrimination-when the seller does not know buyers' characteristics. That paper explains, for example, Thanksgiving turkey as a loss leader because those who want a turkey will also buy many other goods, such as side dishes. Another rationale for loss-leader pricing is that the seller gains some monopoly power once a customer enters the store. For example, Ellison (2005) provides a theory of add-on pricing and argues that hotels advertise lower prices for accommodation in hopes of selling add-ons, such as minibar items, at higher prices. In and Wright (2014) show that firms lose money on customers who buy a basic version of a good while making profits on customers who buy an upgraded version of it. In our paper, the mall prices parking as a permanent loss leader by having public transportation riders internalize the discomfort externalities that they impose on each other.

This paper is organized as follows. Section 2 presents the base model and derives the main results. Section 3 analyzes the social optimum. Section 4 discusses six extensions of the base model: private provision of transportation service, shuttle service provided by the mall, traffic congestion created by cars, adding passengers who use public transportation for purposes other than shopping at the mall, competition between malls, and having the mall sell multiple goods. Section 5 concludes. An appendix derives the equilibrium with a more general cost function and analyzes corner solutions.

\section{Core analysis}

There is a monopolist shopping mall selling a homogeneous good at a nonnegative sales price $P .^{7}$ We assume that no customers can walk to the mall and that the road system has enough capacity that traffic is not congested-thus, the mall is suburban. ${ }^{8}$ We use a $c$ subscript to denote cars, and we refer to public transportation as "bus" and use a $b$ subscript to denote it. The mall provides parking spaces to shoppers who travel by car. Its marginal cost of providing a parking space is $m_{c}>0$. The parking fee is denoted by $t \geq 0$. Both $P$ and $t$ are chosen by the mall and are common knowledge.

Without loss of generality, we normalize the marginal cost of providing the good in the mall to zero. ${ }^{9}$ The total mass of customers is $N$. We refer to them as shoppers if they visit the mall. Each shopper buys one unit of the good. Each customer has a value of the good $v$, which is a random variable with a cumulative distribution function of $G(v)$ and a probability density function of $g(v)$, which is strictly positive on $[0, \bar{v}]$. We assume that $\bar{v}$ is high enough that some customers always shop, and that $G(v)$ satisfies the monotone hazard rate property that $g(v) /(1-G(v))$ is non-decreasing, which ensures that the mall's profit function is concave. ${ }^{10}$

Customers make two decisions: whether to visit the mall, and if so, which travel mode to use. A customer who stays at home gets a reservation payoff of $r$. A shopper who visits the mall by car pays the parking fee of $t$ and has a fuel cost of $\kappa \cdot{ }^{11}$ A shopper who visits the mall by bus pays a fare of $f$, and incurs a discomfort cost of $d_{b}\left(N_{b}\right)$, where $N_{b}$ is the number of

\footnotetext{
${ }^{6}$ Chen and Rey (2012) is an exception. They concentrate on the competition between a large firm selling a broad range of goods and small fringe firms selling a narrower set. In order to discriminate between multi-stop shoppers and one-stop shoppers, the large firm prices some of the goods sold by the smaller firms below their cost while raising the sales prices of other goods.

${ }^{7}$ There are three important points to note here. First, as in Hasker and Inci (2014), we take the mall and stores as one economic entity in the determination of parking fees. The reality is more complicated. The mall, in fact, does not operate any of the stores but rather it is a two-sided platform. The tenants' ability to reflect parking costs into the sales prices of goods and services varies depending on the rental contracts and pricing policies. Nevertheless, as evidenced by Wheaton (2000) and Gould et al. (2005), rental contracts in malls are usually functions of a percentage of stores' revenue. Thus, modeling the mall and stores as one entity is harmless for our purposes. Moreover, one can also think of supermarkets, retailers, or department stores, that control both parking fees as well as sales prices independently. Second, although in reality malls are in competition with each other, they have local monopoly power. Thus, our analysis of a monopolist mall is a good approximation. Section 4.5 provides two reduced-form ways of modeling competition. Third, having only one good in the model is obviously a simplification. In reality, some goods are bulky and hard to carry by public transportation. We work out one such case in Section 4.6 and show that our main results continue to hold.

${ }^{8}$ Section 4.3 extends the model to allow for traffic congestion externalities created by cars.

9 Appendix A.1 shows that our main result holds even with a more general cost function.

10 The monotone hazard rate property is satisfied by many common distributions. It was originally constructed to describe failure rates. For example, the probability that a light bulb fails at time $u$ conditional on having lasted up to that time is clearly not decreasing. In our setting, the monotone hazard rate property is equivalent to having a log-concave demand curve, and it means that as $v$ increases the firm is losing a larger and larger fraction of its customers. It only requires that the density is not decreasing too fast. For example, the density of the normal distribution is (eventually) decreasing but satisfies this property. Clearly, the uniform distribution also satisfies this property. The exponential distribution is at the boundary with a constant hazard rate.

11 We assume that all shoppers have a car and that they have a common origin and common destination so that the fuel cost does not vary among them. Moreover, as in Voith (1998), we abstract from the fixed costs associated with car ownership because these fixed costs are sunk at the moment when
} 
shoppers who travel to the mall by bus. We assume that the marginal discomfort cost of riding the bus is always positive, or that $d_{b}^{\prime}\left(N_{b}\right)>0$, and it is convex, or $d_{b}^{\prime \prime}\left(N_{b}\right) \geq 0 .{ }^{12}$

The city maximizes social welfare by choosing the bus fare $f$. The marginal cost of bus service (per passenger) is $m_{b}>0$.

The sequence of events is as follows. First, the city announces the bus fare $f$. Then, the mall decides on the sales price of the good $P$ and the parking fee $t$. Finally, customers make their decisions of whether to travel to the mall, and if so, which travel mode to choose. We solve the model by backward induction, starting with the shopper's decision of which travel mode to use.

\subsection{Shoppers}

A shopper travels to the mall by car if he obtains a payoff that is at least as high as what he would obtain by traveling to the mall by bus, $v-P-t-\kappa \geq v-P-f-d_{b}\left(N_{b}\right)$. Note that $v-P$ cancels out, thus the decision rule is solely cost minimization: $t+\kappa \leq f+d_{b}\left(N_{b}\right)$. Similarly, a shopper travels to the mall by bus if he obtains a payoff that is at least as high as what he would obtain by traveling to the mall by car, $v-P-f-d_{b}\left(N_{b}\right) \geq v-P-t-\kappa$, which simplifies to $f+d_{b}\left(N_{b}\right) \leq t+\kappa{ }^{13}$ Thus, $N_{b}$ is determined by the equilibrium condition

$$
f+d_{b}\left(N_{b}\right)=t+\kappa .
$$

This is Wardrop's first principle, stating that shoppers sort between car and bus until neither travel mode is strictly better. ${ }^{14}$

The decision of a customer to become a shopper does depend on $v-P$. He must be getting a payoff that is at least as high as his reservation payoff of $r$, otherwise, he would have stayed at home. This specifies the marginal shopper, who is indifferent between visiting the mall (by either travel mode) and staying at home,

$$
\tilde{v}-P-t-\kappa=r,
$$

where $\tilde{v}$ is the value of the good to the marginal shopper.

Given the marginal shopper's valuation $\tilde{v}$, the number of shoppers at the mall is $(1-G(\tilde{v})) N$. In the main text, we characterize the interior equilibrium in which each travel mode is used by some number of shoppers. ${ }^{15}$ In particular, we assume that both $N_{b}$ and $N_{c}$ are strictly between zero and $(1-G(\tilde{v})) N$, where $N_{c}$ is the number of shoppers who visit the mall by car. Hence, the third equilibrium condition is

$$
N_{c}+N_{b}=(1-G(\tilde{v})) N .
$$

This last equilibrium condition is just an accounting identity that says shoppers either travel by car or bus. Notice that in this model we cannot be sure which shopper uses which mode. We can only know the total number of shoppers in each group.

\subsection{The shopping mall}

The mall maximizes its profit given the equilibrium conditions we just derived, Eqs. (1)-(3). There are $N_{b}$ shoppers who travel to the mall by bus, and since each buys only the good from the mall, the mall gets revenue of $P$ from each. There are $N_{c}$ shoppers who travel to the mall by car. They pay for both the good and parking, but the mall incurs a cost of $m_{c}$ for each parking space it provides. Thus, the revenue from each car driver is $P+t-m_{c}$. As a result, the mall's total profit is

$$
\Pi(P, t)=P N_{b}+\left(P+t-m_{c}\right) N_{c}
$$

shoppers make their decisions to travel to the mall. In some sense, we analyze the short-run equilibrium where travel costs do not alter car ownership decisions.

12 Thus, if there are more passengers on the bus, the discomfort cost will be higher. In reality, the discomfort cost is probably not very sensitive to the number of passengers up to the point where all seats are taken in the bus. It then starts rising. We could incorporate such a cost function at the expense of creating an additional and trivial case in which there is no discomfort cost. See de Palma et al. (2015) for more realistic modeling. There could also be positive externalities associated with public transportation ridership. The well-known Mohring Effect tells that frequency of public transportation would be increased as a result of increased ridership, which could benefit all passengers via decreased waiting times. We think that negative externalities due to discomfort are relatively more important in many cases, especially when ridership is over some critical threshold.

13 These inequalities are weak because they represent possible choices by the shoppers. If they hold with equality, then a shopper may choose either mode. Equilibrium will require that the proper number use each mode.

14 While we formally assume that all shoppers have access to both cars and buses, the Wardrop principle relies only on one observable condition: some shoppers who have cars use the bus and similar shoppers use cars. With the rise of car-sharing services like Zipcar and Car2go, this condition is even easier to satisfy. Of course, in reality, the Wardrop principle might not hold for some groups. For example, shoppers without cars must use the bus, and those who are planning on making multiple stops might need to use their cars. We only need the Wardrop principle to hold for the marginal customer. In general, shoppers' socio-demographic attributes and factors relating to the built environment affect mode choice. However, due to large differences in individual travel patterns, the impacts in terms of sign and magnitude are different in different studies. Factors affecting mode choice include the purpose and time of travel, job sector, valuation of time, culture, location of travel, urban structure, population density, diversity, quality of public transportation, traffic congestion, other transport fees, land use policy, and types of good. Note that many of these variables are correlated with each other. For example, valuation of time is related to education and occupation. Given that, our model captures most of the critical factors in mode choice for shopping. Buehler (2011) and Popovich and Handy (2015) provide a comprehensive review of the determinants of mode choice.

15 Appendix A.2 derives the corner solutions in which all travel is by car or bus. 
Note that $N_{b}$ and $N_{c}$ are implicit functions of $P$ and $t$ through the equilibrium conditions. The first-order conditions for the mall's profit-maximization problem are

$$
\begin{aligned}
& \frac{\partial \Pi(P, t)}{\partial P}=N_{b}+N_{c}+P \frac{\partial N_{b}}{\partial P}+\left(P+t-m_{c}\right) \frac{\partial N_{c}}{\partial P}, \\
& \frac{\partial \Pi(P, t)}{\partial t}=N_{c}+P \frac{\partial N_{b}}{\partial t}+\left(P+t-m_{c}\right) \frac{\partial N_{c}}{\partial t} .
\end{aligned}
$$

We use equilibrium conditions to derive the partial derivatives that appear on the right-hand sides of these first-order conditions. With respect to $P$, they are

$$
\frac{\partial \tilde{v}}{\partial P}=1, \quad \frac{\partial N_{b}}{\partial P}=0, \quad \frac{\partial N_{c}}{\partial P}=-g(\tilde{v}) N .
$$

The first expression here is quite obvious: For every unit the sales price increases, the marginal shopper's valuation must increase by the same amount. The other expressions are less transparent. Why is the number of shoppers coming by bus unaffected by the sales price even if, for example, all the marginal shoppers are coming by bus? The Wardrop principle stated in Eq. (1) says that when the sales price of the good increases, customers with lower valuations choose to stay at home instead of visiting the mall. Then shoppers re-sort between car and bus until neither travel mode is strictly better than the other, and all marginal shoppers riding the bus are replaced with some shoppers who were formerly using a car.

With respect to $t$, the partial derivatives are

$$
\frac{\partial \tilde{v}}{\partial t}=1, \quad \frac{\partial N_{b}}{\partial t}=\frac{1}{d_{b}^{\prime}}, \quad \frac{\partial N_{c}}{\partial t}=-g(\tilde{v}) N-\frac{1}{d_{b}^{\prime}} .
$$

In this case, the first expression is a little bit less transparent: Even though some shoppers use the bus, the marginal shopper's valuation still increases in a one-to-one ratio with the parking fee. Again, Eq. (1) explains that the marginal shopper is indifferent between different travel modes and thus acts as if he is paying the parking fee. The second expression is fairly obvious. The negative parking fee is a shadow price for bus riders, and thus bus ridership increases in response to an increase in the parking fee. The third expression is an accounting identity. Now $N_{c}$ decreases in response to an increase in the parking fee for two reasons. First, the marginal shopper's valuation has increased, i.e., the number of shoppers visiting the mall has decreased $(-g(\tilde{v}) N)$. Second, some shoppers have switched to the bus $\left(-1 / d_{b}^{\prime}\right)$.

The accounting identity we just discussed is also true for the sales price, and to be specific, differentiating Eq. (3) shows that

$$
-\frac{\partial \tilde{v}}{\partial x} g(\tilde{v}) N=\frac{\partial N_{b}}{\partial x}+\frac{\partial N_{c}}{\partial x}
$$

for any exogenous $x$. Surprisingly, this implies that the impacts of $P$ and $t$ on demand are the same. They both result in a loss of $g(\tilde{v}) N$ shoppers. Therefore, one can consider the marginal revenue impact of $P$ and $t$, holding the number of shoppers constant. Obviously, for $t$, this is only the number of shoppers who visit the mall by car, or $N_{c}$, while for $P$ it is $N_{b}+N_{c}$, which is higher. Thus, the only reason to raise $t$ is to cover the direct cost of parking. Once this is accounted for, all further increases will be in the sales price. In fact, we find that $t$ is not raised enough to even cover its cost.

Parking can be thought of as an add-on, or mixed bundling, as Adams and Yellen (1976) refer to it. The mall sells the good bundled with parking to the shoppers who travel by car, and only the good to the shoppers who travel by bus. The bundled good of parking is offered at a low price to attract customers. In Adams and Yellen (1976), the two goods in the bundle are independently valued goods-neither substitutes nor complements. In our setting, they are independent goods for an individual shopper who travels to the mall by bus because the value of a parking space is zero for him, whereas they are perfect complements for an individual shopper who travels to the mall by car. However, at a market level, which is more of a concern for the mall's pricing, they are partial complements. For those who travel to the mall by car, they are perfect complements, and the others are indifferent over all parking fees. ${ }^{16}$ Like Telser (1979), we find that pricing one of these goods below marginal cost is optimal. ${ }^{17}$

After substituting for the partial derivatives, we find that the equilibrium sales price and the parking fee are characterized by

$$
\begin{aligned}
& P^{*}=\frac{1-G(\tilde{v})}{g(\tilde{v})}+N_{b} d_{b}^{\prime}, \\
& t^{*}=m_{c}-N_{b} d_{b}^{\prime},
\end{aligned}
$$

\footnotetext{
${ }^{16}$ At the market level, when the sales price of the good increases, keeping everything else constant, the demand for parking, $N_{c}$, decreases (see that $\partial N_{c} / \partial P=-g(\tilde{v}) N<0$ in Eq. (7)) and when the parking fee increases, keeping everything else constant, the total demand for the good, $(1-G(\tilde{v})) N$, decreases (see that $\partial \tilde{v} / \partial t=1>0$ in Eq. (8)).

17 Telser (1979) concentrates on bundling of complementary goods and shows that pricing at least one of them below its marginal cost can be profitable. Lewbel (1985) generalizes Adams and Yellen's (1976) results to the cases in which customers may perceive commodities as complements or substitutes, including the cases in which the goods are substitutes for some customers and complements for the rest. That paper concludes that bundling does not require complementarity of the goods. Venkatesh and Kamakura (2003) show that marginal costs play an important role in finding the optimal bundling strategy for complements and substitutes.
} 
provided that both prices are weakly positive. However, notice that Eq. (11) might be strictly negative. In this case, because a negative parking fee is not implementable, we have

$$
\begin{aligned}
& P^{*}=\frac{1-G(\tilde{v})}{g(\tilde{v})}+m_{c}, \\
& t^{*}=0 .
\end{aligned}
$$

We can, in fact, state the equilibrium values more generally as follows:

$$
\begin{aligned}
P^{*} & =\frac{1-G(\tilde{v})}{g(\tilde{v})}+\min \left\{N_{b} d_{b}^{\prime}, m_{c}\right\}, \\
t^{*} & =\max \left\{m_{c}-N_{b} d_{b}^{\prime}, 0\right\} .
\end{aligned}
$$

This expression defines the sales price only implicitly because $\tilde{v}$ is affected by $P$. The left-hand side of it is increasing in $P$, while the first term on the right-hand side is decreasing in $P$ (because of the monotone hazard rate) and the second term is independent of $P$. Thus, there is a unique sales price solving this expression.

We should also explain the expression $N_{b} d_{b}^{\prime}\left(N_{b}\right)$ and its inclusion in the sales price when $t^{*}>0$. In our model, the total discomfort cost of the bus passengers, $D_{b}\left(N_{b}\right)$, is

$$
D_{b}\left(N_{b}\right)=N_{b} d_{b}\left(N_{b}\right) .
$$

Hence, marginal cost is $D_{b}^{\prime}=d_{b}+N_{b} d_{b}^{\prime}$. Bus riders already pay $d_{b}$, and the mall charges $N_{b} d_{b}^{\prime}$-the externality each bus rider creates. Why does it do this? It is not to encourage optimal bus usage. ${ }^{18}$ It is instead due to the crowding effect of bus riders. Each bus rider is imposing the cost of $N_{b} d_{b}^{\prime}$ on others, and the mall makes them pay because this cost decreases the number of shoppers coming by bus. This also explains why, if $N_{b} d_{b}^{\prime}$ is too high $\left(t^{*}=0\right)$, the mall only charges them $m_{c}$. In this case, the mall thinks that the best option is for them to come by car, and thus imposes on them the same cost no matter which mode of travel they use. Finally, the monopoly power of the mall is completely captured by the first term, $(1-G(\tilde{v})) / g(\tilde{v})$, thus our result is really a cost-sharing issue rather than a monopoly-power issue. In particular, the mall does not charge bus passengers for their externality because of its market power; it is rather trying to encourage shoppers to use cars. We summarize the key point of this section in the following proposition.

Proposition 1 (Loss-leader pricing - market equilibrium). The equilibrium parking fee, $t^{*}$, is always less than the mall's marginal cost of providing a parking space, $m_{c}$.

Like in the private tolling of roads and the scheduling problem of monopolist airline carriers, the monopolist mall internalizes congestion externalities. In the standard road-tolling problem, there are two routes and flat tolling. Either one of the routes is tolled by a monopolist while the other one is untolled, or both roads are tolled by two different toll operators. In our case, there are two modes of travel. One mode is congestible while the other is not. Both modes are tolled by the same monopolist. It charges $P+t$ if a shopper travels to the mall by car and $P$ if a shopper travels to the mall by bus. Thus, the tolls are differentiated here. Moreover, the congestible mode is also tolled publicly since the city charges a bus fare of $f$ to a shopper who travels to the mall by bus. In the uncongestible mode, the optimal toll is composed of a monopoly mark-up and the marginal cost of providing that mode. In the congestible mode, the monopolist internalizes the external costs of "congestion" by charging a marginal external cost of discomfort in addition to the monopoly mark-up.

\subsection{The city}

The city maximizes welfare, $W(f)$, by controlling the fare, $f$, for the buses it provides. ${ }^{19}$ The welfare is the sum of the customer's net utility and the profit from both the mall and bus system. Because all price terms are simply transfers, welfare simplifies to the total utility of the customers minus the costs. The utility of a customer is $r$ if he stays at home and $v$ if he visits the mall. The cost that a bus rider generates is $m_{b}+d_{b}\left(N_{b}\right)$, and the cost that a car driver generates is $m_{c}+\kappa$. Hence, we have

$$
W(f)=N \int_{0}^{\bar{v}} \max \{r, v\} d G(v)-\left(m_{b}+d_{b}\left(N_{b}\right)\right) N_{b}-\left(m_{c}+\kappa\right) N_{c} .
$$

The first-order condition with respect to $f$ is

$$
\frac{\partial W}{\partial f}=-(\tilde{v}-r) N g(\tilde{v}) \frac{\partial \tilde{v}}{\partial f}-\left(m_{b}+d_{b}\left(N_{b}\right)\right) \frac{\partial N_{b}}{\partial f}-d_{b}^{\prime}\left(N_{b}\right) N_{b} \frac{\partial N_{b}}{\partial f}-\left(m_{c}+\kappa\right) \frac{\partial N_{c}}{\partial f} .
$$

\footnotetext{
${ }^{18}$ As is shown in Section 4.1, if the bus fare is not welfare maximizing, the mall's pricing policy can result in too few or too many shoppers riding the bus.

${ }^{19}$ This section concentrates on a second-best situation in which the city has the ability to control only the bus fare, which is realistic. Section 3 derives the full social optimum, in which it can control all prices.
} 
Using the equilibrium conditions, the partial derivatives with respect to $f$ are given by

$$
\frac{\partial \tilde{v}}{\partial f}=0, \quad \frac{\partial N_{b}}{\partial f}=-\frac{1}{d_{b}^{\prime}}, \quad \frac{\partial N_{c}}{\partial f}=\frac{1}{d_{b}^{\prime}} .
$$

After using these partial derivatives and Eq. (1), the first-order condition simplifies to

$$
\frac{\partial W}{\partial f}=\frac{1}{d_{b}^{\prime}}\left(m_{b}-m_{c}+t-f+d_{b}^{\prime}\left(N_{b}\right) N_{b}\right),
$$

thus, we get

$$
f=m_{b}+t-\left(m_{c}-N_{b} d_{b}^{\prime}\right) .
$$

When $t^{*}>0$, the term in the brackets is equal to the optimal parking fee, thus we have $f^{*}=m_{b}$. Notice that the city does not try to internalize discomfort externalities here since it relies on the mall to handle that issue.

When $t^{*}=0$, the formula for the optimal bus fare becomes

$$
f^{*}=m_{b}+N_{b} d_{b}^{\prime}-m_{c} .
$$

Now the burden of internalization of externalities has been shifted from the mall to the city. The marginal cost of a bus rider is $m_{b}+d_{b}\left(N_{b}\right)+d_{b}^{\prime}\left(N_{b}\right) N_{b}$, of which the passenger pays $d_{b}\left(N_{b}\right)$. Thus, the city charges him for the rest. The opportunity cost of not using the bus is becoming a driver whose marginal cost is $\kappa+m_{c}$, of which the driver pays $\kappa$. Thus, the rest must be subtracted from the bus fare charged to the shopper. In this case, we have $t^{*}=0$ or $m_{c}-N_{b} d_{b}^{\prime} \leq 0$. Thus, $N_{b} d_{b}^{\prime}-m_{c} \geq 0$, which means that the bus fare is higher than the marginal cost of bus service, $f^{*} \geq m_{b}$.

This result is somewhat surprising because society might want to subsidize bus travel $\left(f^{*}<m_{b}\right)$ to compensate for the mall's status as a monopolist. This subsidy does not occur because we have a constant cost of using a car. This implies that the Wardrop principle only determines $N_{b}$ and that the bus fare has no impact on the marginal customer $(\partial \tilde{v} / \partial f=0)$. However, if the cost of using a car was not constant, we would be exactly in the model of Section 4.3, where car drivers create a congestion externality. In that case, $f^{*}<m_{b}$ is possible.

Another thing to note is that the mall does decrease the sales price in response to a higher bus fare. The Wardrop principle stated in Eq. (1) results in $\tilde{v}$ being independent of $f$, and Eq. (19) states that the number of bus riders is decreasing in the bus fare, and thus implicit differentiation of Eq. (14) reveals that $P$ is decreasing in $f$, given that the discomfort cost function is convex, which is empirically supported. Thus, when the bus fare increases, the mall decreases the sales price (and increases the parking fee).

\section{Social optimum}

We now consider the full social optimum when the planner determines not only the bus fare but also all prices at the mall. The welfare is still expressed by Eq. (17), but the planner now maximizes it over all three prices, $P, t$, and $f$. The first-order conditions with respect to $x \in\{t, P, f\}$ are given by

$$
\frac{\partial W}{\partial x}=-(\tilde{v}-r) N g(\tilde{v}) \frac{\partial \tilde{v}}{\partial x}-\left(m_{b}+d_{b}\left(N_{b}\right)+N_{b} d_{b}^{\prime}\right) \frac{\partial N_{b}}{\partial x}-\left(m_{c}+\kappa\right) \frac{\partial N_{c}}{\partial x} .
$$

After simplification and substitution, one can see that if $\partial W / \partial P=0$ and $\partial W / \partial f=0$, then $\partial W / \partial t=0$, or we have collinearity. Thus, we do not have a unique solution. Our binding conditions are

$$
\begin{aligned}
& t^{s o}=m_{c}-P^{s o}, \\
& f^{s o}=m_{b}+t-\left(m_{c}-N_{b} d_{b}^{\prime}\right),
\end{aligned}
$$

where the so superscript represents the social optimum.

To achieve the social optimum, the planner charges the customers their social marginal cost. A shopper who travels to the mall by car pays $P+t+\kappa$. This should be equal to the social marginal cost he creates, which is the sum of the marginal cost of the good (zero), the marginal cost of a parking space $\left(m_{c}\right)$, and the cost of his fuel consumption $(\kappa)$ :

$$
P+t+\kappa=m_{c}+\kappa .
$$

A bus passenger pays $P+f+d_{b}\left(N_{b}\right)$. His social marginal cost is composed of the direct marginal cost of using the bus $\left(m_{b}\right)$, the discomfort cost he himself incurs $\left(d_{b}\left(N_{b}\right)\right)$, and the marginal external cost of discomfort he imposes on others $\left(N_{b} d_{b}^{\prime}\right)$. Again, in the full social optimum, the total payment by a shopper who travels to the mall by bus should be equal to the social marginal cost he creates:

$$
P+f+d_{b}\left(N_{b}\right)=m_{b}+d_{b}\left(N_{b}\right)+N_{b} d_{b}^{\prime} .
$$

It is tempting to think that in the social optimum we should set $P$ equal to the marginal cost of the good, which is zero here, but this is only one way of achieving the social optimum. In all others, sales price is above marginal cost. In fact, in practice, there are many other reasons to have $P>0$ in the social optimum, even though the marginal cost of providing the 
good is zero. For example, it would simplify collection of fees if $P=\min \left\{m_{c}, m_{b}+N_{b} d_{b}^{\prime}\right\}$ and either parking or the bus is free. Furthermore, free parking has both strong political support (see De Borger and Russo, 2015) and tradition (see the historical reviews in Shoup, 2005), thus, it might be easier to adjust other prices accordingly. Finally, an important intermediate state between full price control and no price control is one where society takes control of parking as well as public transportation. In this case, there might be many reasons why the stores have market power, and society would want to compensate for this by lowering other fees. ${ }^{20}$ The following proposition records our results in this section.

Proposition 2 (Loss-leader pricing - social optimum). As long as the sales price is strictly above its marginal cost, parking is a loss leader in the social optimum.

We should note here that, as we show in Section 4.4, if there are other passengers on the bus and the social optimum is unconstrained, then loss-leader pricing of parking is the only possibility.

\section{Extensions}

Real life is more complicated than any model. In this section, we consider six important extensions of our base model. First, we consider how the solution changes if there is a private, profit-maximizing bus service. Second, we analyze what happens if the mall provides shuttle service on its own. Third, we explore an environment where road capacity is limited and cannot be easily expanded so that there is congestion. Fourth, we analyze what happens if there are passengers who ride the bus for purposes other than shopping at the mall. Fifth, we reflect on two reduced-form ways of modeling competition between malls. Sixth, we deliberate over what happens if the mall sells multiple goods.

\subsection{Private provision of bus service}

Our first topic is to explore what might happen if the bus service was provided by private suppliers. Not only is this the case in many countries, but it also allows us to analyze a city that is not welfare maximizing. As we shall show, in most cases, private provision of bus service results in the wrong number of people riding the bus.

We consider the two polar cases of a perfectly competitive and a monopoly bus system. Obviously, in the case of perfect competition, free entry implies that $f_{p}=m_{b}$, where the $p$ subscript is for competitive private provision. In the case of a monopoly, the fare is chosen to maximize profits, $\Pi_{b}(f)=\left(f-m_{b}\right) N_{b}$, and the first-order condition is given by

$$
\frac{\partial \Pi_{b}}{\partial f}=N_{b}+\left(f-m_{b}\right) \frac{\partial N_{b}}{\partial f},
$$

which yields $f_{m}=m_{b}+N_{b} d_{b}^{\prime}$, where the $m$ subscript is for monopoly.

A comparison of the perfectly competitive and monopolist bus fares with the socially optimal bus fare, shown in Eq. (25), is fruitful. When the parking fee is positive, we have $f^{s o}=f_{p}=m_{b}<f_{m}$, otherwise $f_{p}<f^{\text {so }}<f_{m}$. Thus, we conclude the following:

Proposition 3 (Private bus fare). Unless the mall charges for parking and buses are provided in a perfectly competitive market, private provision of bus service results in the wrong number of bus riders. Too many shoppers ride the bus if there is free parking and competitive provision, too few if the provider is a monopolist.

Malls rarely charge a fee for parking. Thus, in general, we conclude that private provision of bus service results in the wrong number of bus riders. We should, however, emphasize that this extension does not change our core result: Even if parking is charged for, it will be a loss leader.

\subsection{Shuttle service}

In some countries, such as Russia and Turkey, some malls offer shuttle services to their customers. When the mall offers the bus service on its own, its profit function is

$$
\Pi\left(P, t, f_{s}\right)=\left(P+f_{s}-m_{s}\right) N_{s}+\left(P+t-m_{c}\right) N_{c},
$$

where $f_{s}$ is the shuttle service fare, $m_{S}$ is the cost of providing the shuttle service, and $N_{S}$ is the number of shoppers using the shuttle service.

The comparative statics properties of $N_{S}$ here are the same as those of $N_{b}$ of the base model. Likewise, $f_{s}$ behaves in the same way as $f$ of the base model. Assuming that the mall prefers to provide both parking and shuttle service, we can look for an interior solution by equating the first-order conditions for maximization of Eq. (29) to zero. This exercise reveals that the equilibrium is not uniquely defined, although the full prices paid by bus and car riders are still unique and given by

$$
P+t=\frac{1-G(\tilde{v})}{g(\tilde{v})}+m_{c},
$$

\footnotetext{
${ }^{20}$ If there were a significant number of shoppers who visited the mall by foot or bicycle, then the sales price must be equal to marginal cost in the social optimum, but this would be a model of an urban mall.
} 


$$
P+f_{s}=\frac{1-G(\tilde{v})}{g(\tilde{v})}+m_{s}+N_{s} d_{s}^{\prime},
$$

where $d_{s}^{\prime}$ is the derivative of the discomfort cost associated with crowdedness in the shuttle, $d_{s}\left(N_{s}\right)$. The first expression says that the full price charged to a car rider should just be a monopoly mark-up over the full cost of providing the good to him. The second one says the same thing, but this time, the full price also includes the marginal external cost that a bus rider imposes on others, which the mall fully internalizes via its pricing. Parking is not necessarily a loss leader in this setting. However, malls usually offer shuttle services for free. In that case, the parking fee is $m_{c}-m_{b}-N_{s} d_{s}^{\prime}$, which is again less than the cost of providing parking. The opposite is not true. When parking is free, shuttle service is not necessarily a loss leader. We record this result in the following proposition.

Proposition 4 (Shuttle service). If the mall provides shuttle service for free, parking is a loss leader. If parking is free (and thus still a loss leader), shuttle service is not necessarily a loss leader.

The non-uniqueness of parking fees and shuttle service fares is not surprising. The mall is interested in the full price it receives from each shopper group (i.e., $P+t$ for car riders and $P+f_{s}$ for bus riders) and, because customers are risk neutral and there is no uncertainty associated with a purchase, the mall is free to choose any $P$, $t$, and $f_{s}$ it wants, as long as it satisfies Eqs. (30) and (31). Then, one equilibrium selection criterion to pick among multiple equilibria in our setting is risk aversion. A tiny bit of customer risk aversion related to the uncertainty associated with making a purchase is sufficient to lead to an outcome where both parking and shuttle service are provided for free. This is because, when the mall is risk neutral and customers are risk averse, the mall has the incentive to insure both bus and car riders as much as it can. Since providing full insurance requires subsidized parking, it provides free parking. This is the most common outcome we observe in real life, and it definitely involves loss-leader pricing. Even without risk aversion, a tiny bit of transaction cost associated with collecting parking and shuttle fees would result in the mall choosing the zero-fee-for-both-services equilibrium.

\subsection{Traffic congestion}

In our base model, we assume that the road system is not congestible. Clearly, this is not the case in urban areas, and indeed malls themselves sometimes cause traffic congestion.

For simplicity, we assume that the public transportation system does not increase congestion on roads, and road congestion does not affect public transportation. This is especially true in the case of a subway (or metro train) system. In the case of buses, one could assume that there are dedicated bus lanes. Given this simplification, the cost of traffic congestion for car drivers is $d_{c}\left(N_{c}\right)$, where we assume $d_{c}^{\prime}>0$. The modified equilibrium conditions (Eqs. (1)-(3)) are as follows:

$$
\begin{aligned}
& f+d_{b}\left(N_{b}\right)=t+\kappa+d_{c}\left(N_{c}\right), \\
& \tilde{v}-P-t-\kappa-d_{c}\left(N_{c}\right)=r, \\
& N_{c}+N_{b}=(1-G(\tilde{v})) N .
\end{aligned}
$$

In this generalization, the partial derivatives are more complex. Where $\Delta=d_{b}^{\prime}+d_{c}^{\prime}+N g(\tilde{v}) d_{b}^{\prime} d_{c}^{\prime}>0$, they are

$$
\begin{aligned}
& \frac{\partial \tilde{v}}{\partial P}=\frac{d_{b}^{\prime}+d_{c}^{\prime}}{\Delta}, \quad \frac{\partial N_{b}}{\partial P}=-\frac{d_{c}^{\prime} g(\tilde{v}) N}{\Delta}, \quad \frac{\partial N_{c}}{\partial P}=-\frac{d_{b}^{\prime} g(\tilde{v}) N}{\Delta}, \\
& \frac{\partial \tilde{v}}{\partial t}=\frac{d_{b}^{\prime}}{\Delta}, \quad \frac{\partial N_{b}}{\partial t}=\frac{1}{\Delta}, \quad \frac{\partial N_{c}}{\partial t}=-\frac{d_{b}^{\prime} g(\tilde{v}) N+1}{\Delta}, \\
& \frac{\partial \tilde{v}}{\partial f}=\frac{d_{c}^{\prime}}{\Delta}, \quad \frac{\partial N_{b}}{\partial f}=-\frac{d_{c}^{\prime} g(\tilde{v}) N+1}{\Delta}, \quad \frac{\partial N_{c}}{\partial f}=\frac{1}{\Delta} .
\end{aligned}
$$

The sign of partial derivatives has not changed, except some zeros now have a definite sign.

When the mall charges for parking, the equilibrium is characterized by

$$
\begin{aligned}
P^{*} & =\frac{1-G(\tilde{v})}{g(\tilde{v})}+N_{b} d_{b}^{\prime}, \\
t^{*} & =m_{c}+N_{c} d_{c}^{\prime}-N_{b} d_{b}^{\prime} .
\end{aligned}
$$

We now see that parking is not always a loss leader. It is a loss leader only when the marginal discomfort externality of the bus is higher than the marginal traffic congestion externality of the car (i.e., $N_{c} d_{c}^{\prime}<N_{b} d_{b}^{\prime}$ ). In such a case, it is easier to attract customers by having the bus riders internalize the discomfort externalities that they impose on each other than by having car users internalize the traffic congestion that they impose on each other. Looking at the total amount paid by each type of shopper, one immediately realizes that there is a shell game going on. First, everyone pays the marginal externality of public transportation riders, then car riders have this externality subtracted from their parking fee, and then the marginal 
externality of car riders is added in. So, everyone pays their marginal externality, but car drivers have a more complicated fee-collection program.

The condition for free parking is likewise more complex. Parking will now be free if and only if $m_{c}+N_{c} d_{c}^{\prime} \leq N_{b} d_{b}^{\prime}$. One should not underestimate the marginal externality of public transportation nor overestimate that of cars. See de Palma et al. (2015) for estimates of the marginal discomfort externality in public transportation and recognize that shoppers may carry bulky packages. Recognize also that if there is traffic congestion only in the city center, then the traffic congestion for a trip might be low, even though it is high near the mall and one might have to search for a parking space.

When parking is free, the formula for the sales price is more complicated:

$$
\begin{aligned}
P^{*} & =\frac{1-G(\tilde{v})}{g(\tilde{v})}+\frac{d_{b}^{\prime}}{d_{b}^{\prime}+d_{c}^{\prime}}\left((1-G(\tilde{v})) N d_{c}^{\prime}+m_{c}\right), \\
t^{*} & =0 .
\end{aligned}
$$

The sales price still contains the standard monopoly mark-up, $(1-G(\tilde{v})) / g(\tilde{v})$, however, the second term is harder to analyze. We can only state that it is less than $N_{b} d_{b}^{\prime}$.

A useful general formula for the sales price is

$$
P^{*}=\frac{1-G(\tilde{v})}{g(\tilde{v})}+\Delta t^{*}
$$

where $\Delta t^{*}=\min \left\{N_{b} d_{b}^{\prime},\left(d_{b}^{\prime}\left((1-G(\tilde{v})) N d_{c}^{\prime}+m_{c}\right)\right) /\left(d_{b}^{\prime}+d_{c}^{\prime}\right)\right\}$. We can use this to simplify the socially optimal bus fare, which is now a function of both the sales price and the parking fee:

$$
f^{*}=m_{b}-\frac{1-G(\tilde{v})}{g(\tilde{v})} \frac{d_{c}^{\prime} g(\tilde{v}) N}{1+d_{c}^{\prime} g(\tilde{v}) N}+\left(N_{b} d_{b}^{\prime}-\Delta t^{*}\right) \frac{d_{c}^{\prime} g(\tilde{v}) N}{1+d_{c}^{\prime} g(\tilde{v}) N}+\left(t^{*}-\left(m_{c}+N_{c} d_{c}^{\prime}-N_{b} d_{b}^{\prime}\right)\right) \frac{1}{1+d_{c}^{\prime} g(\tilde{v}) N} .
$$

We have that $t^{*}-\left(m_{c}+N_{c} d_{c}^{\prime}-N_{b} d_{b}^{\prime}\right) \geq 0$ and $N_{b} d_{b}^{\prime}-\Delta t^{*} \geq 0$, thus the impact of the last two terms is weakly positive. However, the second term is strictly negative. It is the monopoly mark-up, $(1-G(\tilde{v})) / g(\tilde{v})$, multiplied by a number that is between zero and one. Thus, it is possible that the bus fare might be below its marginal cost and indeed could be free. In fact, if parking is charged for, we can be certain that the optimal bus fare is strictly below its marginal cost because $t^{*}-\left(m_{c}+N_{c} d_{c}^{\prime}-N_{b} d_{b}^{\prime}\right)=N_{b} d_{b}^{\prime}-\Delta t^{*}=0$. We should note that this effect has to be weighed against the fact that, in general, the marginal cost of providing bus service is large and significant. This could explain why free public transportation is uncommon. ${ }^{21}$

\subsection{Other passengers on the bus}

Obviously, bus services provided by the city are not only for the customers of the mall. Usually, people ride the bus for other purposes. Does this change the main insights of this paper? Here we show that our results are enforced in this more realistic situation. In fact, our base model is nested in the more general model we present here.

Assume now, in addition to shoppers, there are also $N_{0}$ other passengers who ride the bus for purposes other than shopping at the mall. We first concentrate on the equilibrium. The Wardrop principle is now given by

$$
f+d_{b}\left(N_{b}+N_{o}\right)=t+\kappa
$$

while Eqs. (2)-(7) and (9) remain the same. Hence, Eq. (8) becomes

$$
\frac{\partial \tilde{v}}{\partial t}=1, \quad \frac{\partial N_{b}}{\partial t}=\frac{1}{d_{b}^{\prime}\left(N_{b}+N_{o}\right)}, \quad \frac{\partial N_{c}}{\partial t}=-g(\tilde{v}) N-\frac{1}{d_{b}^{\prime}\left(N_{b}+N_{o}\right)} .
$$
by

After going through the same steps we have in the base model, we find that the interior equilibrium is characterized

$$
\begin{aligned}
P^{*} & =\frac{1-G(\tilde{v})}{g(\tilde{v})}+N_{b} d_{b}^{\prime}\left(N_{b}+N_{o}\right), \\
t^{*} & =m_{c}-N_{b} d_{b}^{\prime}\left(N_{b}+N_{o}\right) \geq 0 .
\end{aligned}
$$

Depending on the functional form of $d_{b}(\cdot)$ and the equilibrium value of $N_{b}$, the parking fee we find here can be higher or lower than what we find in the base model. With the assumption of convex crowding costs, however, the parking fee here is expected to be higher. As in the base model, if the parking fee given in Eq. (47) cannot be positive, the mall provides parking for free, and the sales price takes the same form as the one in Eq. (12). In sum, the result that parking is a loss leader holds even with other passengers on the bus.

Proposition 5 (Other passengers on the bus - equilibrium). When there are other passengers using the bus, the mall still prices parking as a loss leader.

\footnotetext{
21 An incomplete list of cities with free public transportation is provided at http://en.wikipedia.org/wiki/Free_public_transport.
} 
Now, turn to the city's problem. Since we are merely extending our base model, we assume that other bus passengers derive an exogenous total benefit of $B_{0}\left(N_{o}\right)$ from bus usage, or that $N_{o}$ maximizes $B_{0}\left(N_{o}\right)-f N_{o}-d_{b}\left(N_{b}^{*}+N_{o}^{*}\right) N_{0}$. Notice that $d_{b}(\cdot)$ is not affected by $N_{0}$, and only the equilibrium values enter in that function because passengers do not really choose the level of externalities. This implies $B_{0}^{\prime}=f+d_{b}$ and $\partial N_{o} / \partial f=1 / B_{0}^{\prime \prime}<0$. With this modification, the social welfare function given in Eq. (17) becomes

$$
W(f)=N \int_{0}^{\bar{v}} \max \{r, v\} d G(v)+B_{o}\left(N_{o}\right)-\left(m_{b}+d_{b}\left(N_{b}+N_{o}\right)\right)\left(N_{b}+N_{o}\right)-\left(m_{c}+\kappa\right) N_{c} .
$$

This time, the partial derivatives with respect to $f$ are given by

$$
\frac{\partial \tilde{v}}{\partial f}=0, \quad \frac{\partial N_{b}}{\partial f}=-\frac{1}{d_{b}^{\prime}}-\frac{\partial N_{o}}{\partial f}, \quad \frac{\partial N_{c}}{\partial f}=\frac{1}{d_{b}^{\prime}}+\frac{\partial N_{o}}{\partial f},
$$

and hence, when the equilibrium parking fee is positive, the bus fare is given by

$$
f=m_{b}+\alpha_{e d}\left[\left(m_{c}+\kappa\right)-\left(m_{b}+d_{b}\right)\right]+\left(1-\alpha_{e d}\right) N_{o} d_{b}^{\prime}
$$

where $\alpha_{e d}=d_{b}^{\prime} /\left(d_{b}^{\prime}-\partial f / \partial N_{o}\right) \in[0,1]$. Thus, the mall internalizes the $N_{b} d_{b}^{\prime}$ portion of the externality while the city ensures that the marginal incentives are correct in the end. The term $\partial f / \partial N_{o}=\left[\partial N_{o} / \partial f\right]^{-1}$ is the slope of the demand curve as it is traditionally graphed, with quantity (i.e., $N_{0}$ ) on the horizontal axis. This term is a weight balancing the difference in direct costs of the modes of transport (i.e., $\left.\left(m_{c}+\kappa\right)-\left(m_{b}+d_{b}\right)\right)$ and the externality cost of the other passengers (i.e., $\left.N_{o} d_{b}^{\prime}\right)-$ the externality cost of shoppers is handled by the mall. Holding the externality $\left(d_{b}^{\prime}\right)$ constant, as demand becomes more elastic (i.e., $\partial f / \partial N_{O} \rightarrow 0$ ), the difference in accounting costs becomes important, and, in fact, in the limit, the bus fare is set at the social opportunity cost of bus travel (i.e., $\left.f=m_{c}+\kappa\right)$. As demand becomes inelastic $\left(\partial f / \partial N_{0} \rightarrow-\infty\right)$, only the externality matters and in the limit $f=m_{b}+N_{o} d_{b}^{\prime}$. If there are no other passengers on the bus, this is equivalent to $\partial f / \partial N_{o} \rightarrow-\infty$ and $N_{o} \rightarrow 0$, in which case, like before, we have $f=m_{b}$.

When the equilibrium parking fee is zero, we find that

$$
f=m_{b}+\alpha_{e d}\left[\left(m_{c}+\kappa\right)-\left(m_{b}+d_{b}\right)\right]+\left(1-\alpha_{e d}\right)\left[\left(N_{b}+N_{o}\right) d_{b}^{\prime}-m_{c}\right] .
$$

Looking at Eqs. (50) and (51), it is clear that the bus fare is undertaking a double duty. It has to trade off the opportunity cost of bus travel with the externality of other passengers. One might expect that this is because the parking fee, $t$, is not socially optimal. If it was, then perhaps the bus fare would simply be equal to the opportunity cost of bus travel. This is precisely what we find if the social optimum is unconstrained (meaning that all optimal variables are naturally positive).

The mall's internalization of crowding costs is limited here because it is interested in internalizing only the part of the externality that affects its business while it has no interest in the crowding costs that other passengers incur. So the city cannot fully rely on the mall to internalize all crowding costs, but it rather internalizes the remaining externality in the market by properly adjusting its bus fare. ${ }^{22}$

In the full social optimum, the planner maximizes Eq. (48) by choosing not just the bus fare but also the sales price and the parking fee. This time, the first-order conditions have a recursive structure. Equating $\partial W / \partial P$ to zero gives $P=m_{c}-$ t. Given this, $\partial W / \partial t=0$ requires that $t=f-m_{b}+m_{c}-\left(N_{b}+N_{o}\right) d_{b}^{\prime}$. Then, finally, $\partial W / \partial f=0$ gives $B_{o}^{\prime}=f+d_{b}=m_{c}+\kappa$. Hence, the social optimum is characterized by

$$
\begin{aligned}
& P^{s o}=\left[\left(\left(N_{b}+N_{o}\right) d_{b}^{\prime}+m_{b}+d_{b}\right)-\left(m_{c}+\kappa\right)\right], \\
& t^{s o}=m_{c}-\left[\left(\left(N_{b}+N_{o}\right) d_{b}^{\prime}+m_{b}+d_{b}\right)-\left(m_{c}+\kappa\right)\right], \\
& f^{s o}=m_{c}+\kappa-d_{b} .
\end{aligned}
$$

In the social optimum, the externality is internalized in the parking fee. Given that $P$ should be weakly positive, we have $t \leq m_{c}$. Thus, if there are other passengers riding the bus, the parking fee is (weakly) lower than the marginal cost of parking, and the parking fee compensates the car riders for the fact they do not impose an externality on others. Intuitively, the cost of bus travel is determined by the opportunity cost of riding the bus, which is the cost of using a car. Since this is pinned down, the parking fee must compensate car drivers for the fact they are not imposing an externality. We summarize our results in the following proposition.

Proposition 6 (Other passengers on the bus - social optimum). When there are other passengers using the bus, parking is a loss leader if the full social optimum is unconstrained.

\footnotetext{
22 This situation is similar to a setting in which two governments toll a serial road link. As De Borger et al. (2007) show, the governments set tolls that are inefficiently high because each one is only concerned about the welfare of its own citizens so that double-marginalization occurs. Our problem is different in the sense that the city maximizes the total welfare of the whole population. In particular, it has the appropriate incentives to internalize any externalities that remain after the mall has internalized the crowding costs incurred by its customers.
} 


\subsection{Competitive shopping mall}

The base model is a model of a monopolist mall. Although malls are in competition with each other in real life, the simplifying assumption of monopoly is quite reasonable because they actually have local monopoly power in their spatial competition. Here, we present some insights on what happens if there is perfect competition.

There are two simple ways in which one can think of competition. The first is the residual-demand curve approach. In this approach, one argues that the mall's demand curve becomes increasingly elastic as the number of competitors increases, and becomes perfectly elastic in the limit as their number approaches infinity. This is equivalent to reducing the monopoly mark-up, $(1-G(\tilde{v})) / g(\tilde{v})$, and, as one can immediately see from Eq. (14), this has no impact on our results other than to reduce the equilibrium sales price.

The other approach is to argue that there is a binding constraint on the profits, and moving towards perfect competition is equivalent to reducing that constraint to zero. This implies that $\partial \Pi / \partial P=\partial \Pi / \partial t>0$. Otherwise, if the mall makes higher profits by raising the sales price than by raising the parking fee, then it should do that. These two constraints yield that $t=m_{c}-d_{b}^{\prime} N_{b}$, just like we have in our base model. The formula for the sales price (determined by the profit constraint) is, however, different. If a profit constraint of $\bar{\pi}$ per shopper is implied, then it is $P=\bar{\pi}+\left(N_{c} /\left(N_{b}+N_{c}\right)\right) d_{b}^{\prime} N_{b}$. Like before, $d_{b}^{\prime} N_{b}$ is replaced with $m_{c}$ if $t^{*}=0$.

\subsection{Multiple goods}

We now consider the case in which the mall sells two different goods rather than one homogenous good. Good 1 is a small item that can be carried in both bus and car, but good 2 is a bulky item that can only be carried by car. Like in the base model, each shopper buys one good from the mall. ${ }^{23}$ Thus, $N_{i}$ customers assign a positive value to good $i$, where $i=1,2$. Note that $N_{1}+N_{2}=N$. We assume that both customer groups have the same reservation payoff, $r$.

The sales price of good $i$ is $P_{i}$, and its marginal cost is $m_{i}{ }^{24}$ The value of the good is $v_{i}$, which is distributed by a cumulative distribution function of $G_{i}\left(v_{i}\right)$ and a probability density function of $g_{i}\left(v_{i}\right)>0$ on the interval [0, $\bar{v}_{i}$ ]. As in the base model, $v_{i}$ is high enough that some customers always end up shopping, and $G_{i}\left(v_{i}\right)$ satisfies the monotone hazard rate property.

The Wardrop principle, stated in Eq. (1), remains the same. However, we now have two marginal customers: one among customers of good 1 and one among customers of good 2. Thus, we have $\tilde{v}_{i}-P_{i}-t-\kappa=r$ for $i=1$, 2. A customer who assigns a positive value to good 1 decides whether to visit the mall, and if so, which travel mode to use. A customer who assigns a positive value to good 2 only decides whether to visit the mall since he does so always by car. Thus, the new accounting conditions are

$$
\begin{aligned}
& N_{b}+N_{c_{1}}=\left(1-G_{1}\left(\tilde{v}_{1}\right)\right) N_{1}, \\
& N_{c_{2}}=\left(1-G_{2}\left(\tilde{v}_{2}\right)\right) N_{2},
\end{aligned}
$$

where $N_{c_{i}}$ is the number of shoppers who visit the mall by car and buy good $i$.

Given the equilibrium conditions, the mall maximizes its profit given by

$$
\Pi\left(P_{1}, P_{2}, t\right)=\left(P_{1}-m_{1}\right) N_{b}+\left(P_{1}+t-m_{1}-m_{c}\right) N_{c_{1}}+\left(P_{2}+t-m_{2}-m_{c}\right) N_{c_{2}}
$$

Like in the base model, $N_{b}, N_{c_{1}}$, and $N_{c_{2}}$ are implicit functions of $P_{1}, P_{2}$, and $t$ through the equilibrium conditions. Using their partial derivatives in the first-order conditions, we find that the interior equilibrium is characterized by

$$
\begin{aligned}
& P_{i}^{*}=m_{i}+\frac{1-G_{i}\left(\tilde{v}_{i}\right)}{g_{i}\left(\tilde{v}_{i}\right)}+N_{b} d_{b}^{\prime}, \\
& t^{*}=m_{c}-N_{b} d_{b}^{\prime} \geq 0,
\end{aligned}
$$

for $i=1,2$. As in the base model, if $m_{c}-N_{b} d_{b}^{\prime}<0$, the mall provides parking for free. Hence, it still wants to internalize the externality caused by bus riders by incorporating it into the sales price of good 1, which is bought by both bus and car riders. The mall decreases the parking fee to compensate buyers of good 1 for the increase in its sales price, from which buyers of good 2 also benefit. However, the mall has no reason to compensate these shoppers; hence, it increases the sales price of good 2 by the amount of compensation in the parking fee. Hence, quite interestingly, the sales price of good 2 also includes the externality term, but for a different reason. The following proposition summarizes our findings.

Proposition 7 (Two goods). Parking is still a loss leader when the mall sells a small good that can be carried by both bus and car and a bulky good that can only be carried by car.

In the two-good world, there are two other cases. The first case is the case in which both goods can be carried by both transportation modes. The second one is the case in which good 1 can be carried by bus and car while good 2 can only

\footnotetext{
23 One can also think of these goods as composite goods. In that case, good 2 represents a large shopping activity.

24 Because there are two goods now, we do not normalize the cost of providing a good to zero. However, it will be clear in the end that making that double normalization would not have an effect on our results.
} 
be carried by bus, which is mere theoretical curiosum. We have shown that our result extends to both cases, for which the proofs are available upon request. Note also that our result obviously extends to any number of goods as long as each shopper buys one good.

\section{Conclusions}

In this paper, we find that parking acts as a loss leader for suburban shopping malls-it is priced artificially low, and often times free, in order to attract business. This result is driven by mode choice. Shoppers can choose between car and public transportation, and, naturally enough, the latter has some crowding costs, which a mall would like to internalize. The only way for internalization to succeed is to increase the sales price of the good. However, an increased sales price will also affect the shoppers who come by car, even though they do not impose any externalities on each other. To compensate them, the mall reduces the parking fee below its marginal cost, and we get loss-leader pricing.

Previous explanations of loss-leader pricing have been seasonal in nature. Our results show that parking is always a loss leader at shopping malls, regardless of the seasonal/holiday cycles. We show that this result holds whether transportation is offered privately or publicly, when the mall sells multiple goods, and when there are other passengers using public transportation. We also show how our result changes when we look at a shopping mall in an urban location, where traffic congestion is important. This analysis begs further exploration of parking fees in an urban setting, where traffic congestion is a significant concern.

Another future research topic is to analyze how sales prices and parking fees interact when the mall price discriminates in parking fees. Price discrimination works via valet parking in the context of shopping malls. Many malls offer valet parking services, although they have cheap (in fact mostly free) parking. Do we still have loss-leader pricing in that context? How is the cost of parking distributed among shoppers who use valet parking and shoppers who park in the parking lot on their own? Last but not least, an empirical test of our theory is the most urgent and fruitful topic for future research.

\section{Acknowledgements}

We would like to thank Jos van Ommeren, Hai Yang, Robin Lindsey, three anonymous referees, seminar participants at Bilkent University and the Tinbergen Institute, and participants at the International Transportation Economics Association Annual Conference 2015 for their very helpful comments. Inci would like to acknowledge financial support from the Turkish Academy of Sciences (Outstanding Young Scientist Award, TUBA-GEBIP) and the recognition by the Science Academy (Turkey) via its Young Scientist Award (BAGEP). All errors are our responsibility.

\section{Appendix A}

\section{A.1. General costs}

In the main text, we assume that the mall provides the good costlessly. As a robustness check, assume now that the cost of providing the good is $h\left(N_{b}+N_{c}\right)$. The mall's profit is now given by

$$
\Pi(P, t)=P N_{b}+\left(P+t-m_{c}\right) N_{c}-h\left(N_{b}+N_{c}\right),
$$

or, equivalently,

$$
\Pi(P, t)=P((1-G(\tilde{v})) N)+\left(t-m_{c}\right) N_{c}-h((1-G(\tilde{v})) N) .
$$

The first-order conditions are

$$
\begin{aligned}
& \frac{\partial \Pi(P, t)}{\partial P}=(1-G(\tilde{v})) N-\left(P-h^{\prime}\right) g(\tilde{v}) N-\left(t-m_{c}\right) g(\tilde{v}) N, \\
& \frac{\partial \Pi(P, t)}{\partial t}=N_{c}-\left(P-h^{\prime}\right) g(\tilde{v}) N-\left(t-m_{c}\right) \frac{d_{b}^{\prime} g(\tilde{v}) N+1}{d_{b}^{\prime}},
\end{aligned}
$$

after substituting for the partial derivative terms. Equating these first-order conditions to zero yields

$$
\begin{aligned}
P^{*} & =\frac{1-G(\tilde{v})}{g(\tilde{v})}+h^{\prime}+d_{b}^{\prime} N_{b}, \\
t^{*} & =m_{c}-d_{b}^{\prime} N_{b} .
\end{aligned}
$$

Hence, even when the marginal cost of providing the good is positive, our main result that the mall prices parking as a loss leader continues to hold. The mall only increases the sales price and, in turn, decreases the number of shoppers coming to the mall, but this does not affect the equilibrium parking fee.

To see that the number of shoppers coming to the mall decreases, note that the marginal shopper's valuation is now given by $\tilde{v}=(1-G(\tilde{v})) / g(\tilde{v})+m_{c}+\kappa+r+h^{\prime}$, which is higher than the marginal shopper's valuation in the base model. 


\section{A.2. Corner solutions}

We consider the two corner solutions in which all shoppers visit the mall either by car or by bus. All shoppers visit the mall by car if and only if $t+\kappa<f+d_{b}(0)$. In that case, the mall's profit is given by

$$
\Pi(P, t)=\left(P+t-m_{c}\right)(1-G(\tilde{v})) N .
$$

Since $\tilde{v}=P+t+\kappa+r$, then $\partial \tilde{v} / \partial P=\partial \tilde{v} / \partial t=1$. Thus, the first-order conditions with respect to $P$ and $t$ are the same and do not yield a unique $\left(P^{*}, t^{*}\right)$ pair.

The equilibrium price of the bundle is

$$
P^{*}+t^{*}=\frac{1-G(\tilde{v})}{g(\tilde{v})}+m_{c} .
$$

The mall can choose any $\left(P^{*}, t^{*}\right)$ pair that satisfies Eq. (A.8) as long as $t^{*}<f+d_{b}(0)-\kappa$ holds. Thus, when all travel is by car, the mall can choose many $(P, t)$ pairs, and parking is a loss leader with some of these pairs. With a bit of risk aversion, however, free parking becomes the unique equilibrium.

All shoppers visit the mall by bus if and only if $t+\kappa>f+d_{b}((1-G(\tilde{v})) N)$. In that case, the mall's profit is given by

$$
\Pi(P, t)=P(1-G(\tilde{v})) N .
$$

The first-order condition with respect to $P$ is

$$
\frac{\partial \Pi(P, t)}{\partial P}=(1-G(\tilde{v})) N-P \frac{\partial \tilde{v}}{\partial P} g(\tilde{v}) N .
$$

Since $\tilde{v}=P+\kappa+d_{b}((1-G(\tilde{v})) N)+r$, then $\partial \tilde{v} / \partial P=1 /\left(1+d_{b}^{\prime} f(\tilde{v}) N\right)$. The equilibrium sales price is

$$
P^{*}=\frac{1-G(\tilde{v})}{g(\tilde{v})}+(1-G(\tilde{v})) N d_{b}^{\prime},
$$

and the mall can choose any $t^{*}$ satisfying $t^{*}>f+d_{b}((1-G(\tilde{v})) N)-\kappa$. Thus, when all travel is by bus, the mall sells only the good. Hence, it does not need to worry about the parking fee as long as the parking fee it would set (if it were to supply parking) encourages no shoppers to visit the mall by car even when the buses are very crowded.

\section{References}

Adams, W., Yellen, J., 1976. Commodity bundling and the burden of monopoly. Quarterly Journal of Economics 90, 475-498.

Arnott, R., 2011. Parking economics. In: de Palma, A., Lindsey, R., Quinet, E., Vickerman, R. (Eds.), A Handbook of Transport Economics. Edward Elgar Publishing Limited, UK, pp. 726-743.

Bakis, O., Inci, E., Senturk, O., 2015. Unbundling Curbside Parking Costs from Housing Prices and Rents. Sabanci University.

Borgers, A., Vosters, C., 2011. Assessing preferences for mega shopping centres: a conjoint measurement approach. Journal of Retailing and Consumer Services $18,322-332$.

Brueckner, J., 2002. Airport congestion when carriers have market power. American Economic Review 92, 1357-1375.

Buehler, R., 2011. Determinants of transport mode choice: a comparison of germany and the USA. Journal of Transport Geography $19,644-657$.

Chen, Z., Rey, P., 2012. Loss leading as an exploitative practice. American Economic Review 102, 3462-3482.

De Borger, B., Dunkerley, F., Proost, S., 2007. Strategic investment and pricing decisions in a congested transport corridor. Journal of Urban Economics 62, $294-316$.

De Borger, B., Russo, A., 2015. The Political Economy of Pricing Car Access to Downtown Commercial Districts. CESifo Working Paper No. 5294. CESifo Group Munich.

DeGraba, P., 2006. The loss leader is a turkey: targeted discounts from multi-product competitors. International Journal of Industrial Organization 24, 613-628.

de Palma, A., Kilani, M., Proost, S., 2015. Discomfort in mass transit and its implication for scheduling and pricing. Transportation Research Part B 71, 1-18. de Palma, A., Lindsey, R., 2000. Private toll roads: competition under various ownership regimes. The Annals of Regional Science 34, $13-35$.

Ellison, G., 2005. A model of add-on pricing. Quarterly Journal of Economics 120, 585-637.

Gillen, D., 1977. Estimation and specification of the effects of parking costs on urban transport mode choice. Journal of Urban Economics 4, 186-199.

Glazer, A., Niskanen, E., 1992. Parking fees and congestion. Regional Science and Urban Economics 22, $123-132$.

Gould, E., Pashigian, B., Prendergast, C., 2005. Contracts, externalities, and incentives in shopping malls. Review of Economics and Statistics 87, 411-422.

Hasker, K., Inci, E., 2014. Free parking for all in shopping malls. International Economic Review 55, 1281-1304.

Haywood, L., Koning, M., 2013. Estimating Crowding Costs in Public Transport. Discussion Paper No. 1293. DIW Berlin, German Institute for Economic Research.

Hensher, D., King, J., 2001. Parking demand and responsiveness to supply, pricing and location in the sydney central business district. Transportation Research Part A 35, 177-196.

Hess, J., Gerstner, E., 1987. Loss leader pricing and rain check policy. Marketing Science 6, 358-374.

$\mathrm{Hu}, \mathrm{S}$., Saleh, W., 2005. Impacts of congestion charging on shopping trips in edinburgh. Transport Policy 12, 443-450.

In, Y., Wright, J., 2014. Loss-leader pricing and upgrades. Economics Letters 122, 19-22.

Inci, E., 2015. A review of the economics of parking. Economics of Transportation 4, 50-63.

International Council of Shopping Centers and Urban Land Institute, 2003. Parking Requirements for Shopping Centers: Summary Recommendations and Research Study Report. Urban Land Institute, Washington.

Kraus, M., 1991. Discomfort externalities and marginal cost transit fares. Journal of Urban Economics 29, $249-259$.

Kroes, E., Kouwenhoven, M., Debrincat, L., Pauget, N., 2013. On the value of crowding in public transport for Ile-de-France. International Transport Forum Discussion Papers, No. 2013/18. OECD Publishing.

Lal, R., Matutes, C., 1994. Retail pricing and advertising strategies. Journal of Business 67, 345-370.

Lewbel, A., 1985. Bundling of substitutes or complements. International Journal of Industrial Organization 3, $101-107$.

Li, Z., Hensher, D., 2011. Crowding and public transport: a review of willingness to pay evidence and its relevance in project appraisal. Transport Policy 18 , 880-887. 
Lindsey, R., West, D., 1997. Spatial price discrimination: the use of parking coupons by downtown retailers. Review of Industrial Organization 12, 417-438. Lindsey, R., West, D., 1998. An empirical analysis of retailer participation decisions in a downtown parking coupon program. Journal of Regional Science 38, $1-22$.

Manville, M., 2013. Parking requirements and housing development: regulation and reform in los angeles. Journal of the American Planning Association 79, 49-66.

Parry, I., Small, K., 2009. Should urban transit subsidies be reduced? American Economic Review 99, 700-724.

Popovich, N.D., Handy, S., 2015. Downtown, strip centers, and big-box stores: Mode choice by shopping destination type in davis, california. Journal of Transport and Land Use 8, 149-170.

Reimers, V., 2013. Convenience for the car-borne shopper: are malls and shopping strips driving customers away? Transportation Research Part A 49 , 35-47. Shoup, D., 2005. The High Cost of Free Parking. American Planning Association, Chicago.

Telser, L., 1979. A theory of monopoly of complementary goods. Journal of Business 52, 211-230.

van der Waerden, P., Borgers, A., Timmermans, H., 2009. Consumer response to the introduction of paid parking in a regional shopping center. Transportation Research Record: Journal of the Transportation Research Board 2118, 16-23.

van Ommeren, J., de Groote, J., Mingardo, G., 2014. Residential parking permits and parking supply. Regional Science and Urban Economics 45, 33-44. van Ommeren, J., Wentink, D., 2012. The (hidden) cost of employer parking policies. International Economic Review 53, $965-978$.

van Ommeren, J., Wentink, D., Dekkers, J., 2011. The real price of parking policy. Journal of Urban Economics 70, 25-31.

Venkatesh, R., Kamakura, W., 2003. Optimal bundling and pricing under a monopoly: contrasting complements and substitutes from independently valued products. Journal of Business 76, 211-231.

Verhoef, E., Nijkamp, P., Rietveld, P., 1996. Second-best congestion pricing: the case of an untolled alternative. Journal of Urban Economics 40, $279-302$.

Voith, R., 1998. Parking, transit, and employment in a central business district. Journal of Urban Economics 44, 43-58.

Wheaton, W., 2000. Percentage rent in retail leasing: the alignment of landlord-tenant interests. Real Estate Economics 28, $185-204$. 